\title{
ANALISIS PENDAPATAN DAN KELAYAKAN USAHA KICIMPRING "SAMISUKA" DI DESA CIBONGAS KECAMATAN PANCATENGAH KABUPATEN TASIKMALAYA
}

\author{
INCOME AND FEASIBILITY ANALYSIS OF KICIMPRING "SAMISUKA" BUSINESS \\ IN CIBONGAS VILLAGE, PANCATENGAH DISTRICT, TASIKMALAYA REGENCY
}

\author{
FITRIYANI ${ }^{1 *}$, TRISNA INSAN NOOR ${ }^{2}$, AGUS YUNIAWAN ISYANTO ${ }^{1}$ \\ ${ }^{1}$ Mahasiswa Fakultas Pertanian Universitas Galuh \\ ${ }^{2}$ Dosen Fakultas Pertanian Universitas Padjajaran \\ *Email: fitriyn2898@gmail.com
}

\begin{abstract}
ABSTRAK
Kicimpring merupakan olahan makanan ringan yang mana bahan bakunya sendiri terbuat dari singkong/ubi kayu, makanan ringan ini sering kali dikatakan salah satu produk olahan dari tanah Sunda. Diharapkan adanya agroindustri ini dapat sedikit mengurangi pengangguran serta memperluas akan lapangan pekererjaan, serta memiliki nilai tambah juga nilai ekonomi tinggi, sehingga perusahaan kicimpring "Samisuka" ini mampu meningkatkan keuntungannya. Penelitian ini tujuannya untuk mengetahui: (1) Pendapatan kicimpring "Samisuka" di Desa Cibongas Kecamatan Pancatengah Kabupaten Tasikmalaya, (2) Besarnya nilai R/C agroindustri kicimpring "Samisuka" di Desa Cibongas Kecamatan Pancatengah Kabupaten Tasikmalaya. Jenis penelitian yang digunakannya adalah jenis penelitian kualitatif dengan menggunakan studi kasus yang berlokasi di Desa Cibongas kecamatan Pancatengah Kabupaten Tasikmalaya. Teknik pengambilan sampelnya dilakukan dengan sengaja (purposive) dengan salah satu pertimbangannya bahwa di Desa Cibongas yang memproduksi kicimpring dengan bahan baku singkong adalah Bapak Enung Suhendi dan satu-satunya perusahan yang telah memiliki Izin Usaha Mikro Kecil (IUMK) dengan Nomor NIB:0248011022243. Hasil penelitian menunjukan: (1) Pendapatan yang diperoleh usaha kicimpring "Samisuka" adalah sebesar Rp 360.811,69 untuk satu kali produksinya, (2) Kelayakan nilai R/C pada agroindustri kicimpring "Samisuka adalah 1,48.
\end{abstract}

Kata Kunci: Pendapatan, R/C, agroindustri

\begin{abstract}
Kicmpring is a processed snack whose raw materials are made from cassavalcassava, this snack is often said to be one of the processed product from the land of Sunda. It is hoped that this agroindustry can slightly reduce unemployment and expand employment opportunities, and has added value as well as high economic value, so that this "Samisuka" kicimpring compny was able to increase its profits. This research aims to find out:(1) "Samisuka" kicimpring income in Cibongas Village, Pancatengah Subdistrict, Tasikmalaya Regency, (2) The value of R/C agroindustry "Samisuka" kicimpring in Cibongas Village, Pancatengah Subdistrict, Tasikmalaya Regency. The type of research used is a qualitative research type usng case studies located in Cibongas Village, Pancatengah District, Tasikmalaya Regency. The sampling technique was done (purposive) with one of the considerations that in Cibongas Village the producer of kicimpring with cassava as raw material Mr. Enung Suhendi and the only company that already has a Micro Small Business License (IUMK) with NIB number: 0248011022243. Research results show: (1) The income earned by the "Samisuka" kicimpring business is Rp 360.811,69 for one time production, (2) The feasibility of $R / C$ value in the "Samisuka" kicimpring agroindustry is 1,48 .
\end{abstract}

Keywords : Income, $R / C$, Agroindustry

PENDAHULUAN 
Pertanian merupakan salah satu sektor yang sangat penting bagi perekonomian Indonesia. Berdasarkan luas lahan dan keragaman agroekosistem peluang pengembangannya sangat besar dan beragam. Namun sampai ini sektor pertanian belum cukup handal untuk mensejahterakan petani, memenuhi kebutuhan sendiri, menghasilkan devisa dan menarik investasi (Wargiono, 2007).

Pengembangan agroindustri merupakan salah satu cara sebagai pembangunan di sektor pertanian. Dimana sektor pertanian mempunyai peran yang penting dalam pertumbuhan ekonomi suatu negara, terutama bagi negara yang bercorak agraris seperti Indonesia. Dengan didukung oleh potensi alam dan keanekaragaman hasil alam yang sangat melimpah dapat menjadi pendukung utama dalam pengembagan agroindustri.

Agroindustri dapat menjadi salah satu alternatif untuk meningkatkan perekonomian masyarakat, salah satunya industri pertanian atau bidang lain yang mendukungnya yang terkait dengan sektor pertanian. Keterkaitan tersebut menjadi salah satu ciri dari negara berkembang yang strukturnya mengalami tranformasi dari ekonomi pertanian (agriculture) menuju industri pertanian (agroindustri). Wujud dari keterkaitan ini adalah dimana sektor pertanian sebagai industri untuk menjadikan produk yang lebih kompetitif, yang nantinya mampu meningkatkan nilai tambah dari hasil pertanian itu sendiri. (Kusmawardani, 2009).

Salah satu komoditas yang banyak digunakan sebagai bahan baku agroindustri adalah singkong. Selain dapat digunakan sebagai penganekaragaman menu rakyat, juga mempunyai prospek yang penting sebagai bahan baku industri. Kebutuhan konsumsi singkong yang terus meningkat belum memiliki suatu artian tanpa disertai adanya upaya untuk meningkatkan nilai tambah secara ekonomi. Dituntut adanya keahlian dari sumberdaya manusia untuk mampu mengolahnya agar produk olahan singkong tersebut dapat dimanfaatkan dalam jangka waktu yang lebih lama dan lebih menarik serta variatif.

Salah satu agroindustri skala kecil yang bahan bakunya terbuat dari singkong ialah produk kicimpring "Samisuka" yang berada di Desa Cibongas Kecamatan Pancatengah Kabupaten Tasikmalaya.

Industri kicimpring "Samisuka" adalah perusahaan kicimpring yang berbahan baku singkong/ubi kayu. Adanya industri pengolahan tersebut membuat hasil pertanian menjadi suatu produk yang memiliki nilai tambah dan nilai ekonomi tinggi, 
sehingga perusahaan industri kicimpring "Samisuka" ini mampu meningkatkan keuntungannya. Besarnya keuntungan yang diperoleh dapat menjadi tolok ukur untuk melihat perkembangannya dalam jangka waktu yang lama. Diharapkan adanya agroindustri kicimpring ini dapat sedikit mengurangi pengangguran serta memperluas akan lapangan pekererjaan. Selain itu, dapat membantu perekonomian di wilayah tersebut yang memberikan dampak secara langsung atau secara tidak langsung.

Perusahaan kicimpring "Samisuka" ini belum diketahui pendapatan dan kelayakannya, sehingga perlu adanya analisis lebih lanjut mengenai pendapatan dan kelayakannya. Untuk menganalisis keberhasilan agroindustri kicimpring tersesbut, maka perlu dilakukan perhitungan biaya dan modal yang digunakan dalam setiap proses produksi. Tujuan dari penelitian ini ialah untuk: (1) Mengetahui pendapatan agroindustri kicimpring "Samisuka" di Desa Cibongas Kecamatan Pancatengah Kabupaten Tasikmalaya untuk satu kali proses produk-sinya. (2) Mengetahui besarnya nilai $\mathrm{R} / \mathrm{C}$ agroindustri kicimpring "Samisuka" di Desa Cibongas Kecamatan Pancatengah Kabupaten Tasikmalaya per satu kali produksi.

\section{METOE PENELITIAN}

Jenis penelitian ini adalah jenis penelitian kualitatif dengan menggunakan studi kasus. Metode penelitian kualitatif adalah prosedur penelitian yang bersifat deskriptif yang menghasilkan data berupa kata yang tertulis atau secara lisan dari orang dan pelaku yang bisa diamati dari orang-orang itu sendiri (Furchan, 2010). Sedangkan yang dimaksud dengan studi kasus ialah tentang penelitian suatu objek yang berkenaan dengan suatu fase spesifik atau khas dari keseluruhan personalitas (Nazir, 2009).

Pada penelitian ini data yang dikumpulkan yaitu terdiri dari data primer dan data sekunder. Data primer ialah data yang mana diperolehnya melalui wawancara ke pengusaha kicimpring

"Samisuka" secara langsung dengan menggunakan kuesioner atau daftar pertanyaan. Sedangkan yang dimaksud data sekunder ialah data yang diperolehnya dari instansi ataupun dinas yang terkait dan ada hubungannya dengan penelitian.

Perusahaan industri kicimpring "Samisuka" dipilih secara sengaja (purposive) sebagai sampel dengan salah satu pertimbangannya bahwa di Desa Cibongas Kecamatan Panctengah 
Kabupaten Tasikmalaya yang memproduksi kicimpring dengan bahan baku singkong adalah Bapak Enung Suhendi, dan merupakan satu-satunya perusahaan yang telah mempunyai Izin Usaha Mikro Kecil (IUMK) dengan nomor NIB : 0248011022243.

Menurut Sugiyono (2010), purposive sampling merupakan suatu cara untuk menentukan sampel penelitian dengan salah satu pertimbangannya bahwa data yang diperoleh diperoleh nantinya bisa lebih representatif.

Besarnya dari biaya yang dikelaurakan, penerimaan kotor, pendapatan bersih dan nilai $\mathrm{R} / \mathrm{C}$ yang diterima oleh agroindustri kicimpring "Samisuka" ini bisa diketahui dengan menggunakan rumus di bawah ini:

1. Analasis total biaya dihitung dengan

menggunakan rumus sebagai berikut (Suratiyah, 2006):

$\mathrm{TC}=\mathrm{TFC}+\mathrm{TVC}$

Keterangan:

TC : Total Cost (biaya total)

TFC : Total Fixed Cost (biaya tetap total)

TVC : Total Variable Cost (biaya variabel total)

2. Analisis penerimaan total (Total Revenue) merupakan hasil dari perkalian antara produksi yang di dapatkan dengan harga jual, dan dihitung dengan menggunakan rumus menurut (Suratiyah, 2006):

$\mathrm{TR}=\mathrm{Y}$. Hy

Keterangan:

TR : Total Revenue (penerimaan total)

Y : Jumlah produk yag dihasilkan (bungkus)

Hy : Harga jual produksi (Rp)

3. Analisis pendapatan merupakan selisih antara penerimaan total (Total Revenue) dan biaya total (Total Cost), dihitung menggunakan rumus menurut (Suratiyah, 2006):

$\mathrm{Pd}=\mathrm{TR}-\mathrm{TC}$

Keterangan:

Pd : Pendapatan

TR : Total Revenue (penerimaan total)

TC : Total Cost (biaya total)

4. Menurut Rodjak (2006), R/C merupakan perbandingan antara penerimaan total dengan biaya total, dan dapat dihitung dengan menggunakan persamaan berikut:

$\mathrm{R} / \mathrm{C}=\mathrm{TR} / \mathrm{TC}$

Keterangan:

TR : Total Revenue (penerimaan total)

TC : Total Cost (biaya total)

Kriteria R/C adalah sebagai berikut:

$\mathrm{R} / \mathrm{C}>1$, maka usaha tersebut menguntungkan.

$\mathrm{R} / \mathrm{C}=1$, maka usaha tersebut tidak mendapatkan keuntungan dan tidak merugi (impas). 
$\mathrm{R} / \mathrm{C}<1$, maka usaha yang dijalankan rugi.

\section{HASIL DAN DISKUSI}

Analisis agroindustri kicimpring produksinya yaitu satu kali berupa perhhitungan biaya ataupun modal, penerimaan kotor, pendapatan bersih dan nilai $\mathrm{R} / \mathrm{C}$.

"Samisuka" dilaksanakan dalam proses

Tabel 6. Rincian Keseluruhan Biaya yang dikeluarkan oleh Agroindustri Kicmpring "Samisuka" untuk Satu Kali Produksi

\begin{tabular}{clrr}
\hline No & \multicolumn{1}{c}{ Biaya } & Jumlah (Rp) & Persentase (\%) \\
\hline $1 . \quad$ Biaya Tetap & & \\
$\quad-\quad$ PBB & 25 & \\
$-\quad$ Penyusutan Alat & $2.254,98$ & \\
\hline Jumlah & $\mathbf{2 . 2 7 9 , 9 8}$ & $\mathbf{0 , 3 0}$ \\
\hline
\end{tabular}

2. Biaya Variabel

Bahan Baku:

- Bawang Merah

- Bawang Putih

18.000

- Kencur

17.500

- Sereh

8.000

- Garam

6.000

- Penyedap Rasa

25.000

- Minyak Goreng

100.000

- Singkong

90.000

- Label

- Steples

3.000

- Plastik $1 / 2$ kg

32.000

- Kayu Bakar

2.500

- Plastik Besar

12.000

- Tenaga Kerja

416.600

- Listrik

833,33

\section{Jumlah}

756.933,33

Total 759.188,31

99,70

Tabel 6 menunjukan bahwa biaya terbesar yang digunakan pada satu kali produksinya kicimpring "Samisuka" adalah biaya variabel yaitu sebesar Rp 756.933,33, karena biaya variabel merupakan biaya yang jumlahnya berubah sebanding dengan perubahan volume kegiatan Menurut Mulyadi (2009:468). Sedangkan dari biaya terendah yang dikeluarkan yaitu biaya tetap sebesar Rp 2.279,98, karena biaya tetap merupakan biaya yang jumlahnya akan tetap dalam volume kegiatan tertentu Menurut Mulyadi (2009:466). Jadi keseluruhan jumlah biaya 
yang dikeluarkan pada satu kali produksinya ialah Rp. 759.188,31.

Tabel 7. Penerimaan Kotor, Biaya Total, Pendapatan Bersih dan Nilai R/C Agroindustri Kicimpring "Samisuka" di Desa Cibongas untuk Satu Kali Produksi

\begin{tabular}{|c|c|c|}
\hline No & Komponen & Nilai (Rp) \\
\hline 1. & Penerimaan & 1.120 .000 \\
\hline 2. & Biaya Total & $759.188,31$ \\
\hline 3. & Pendapatan & $360.811,69$ \\
\hline 4. & $\mathrm{R} / \mathrm{C}$ & 1,48 \\
\hline
\end{tabular}

Tabel 7 menjelaskan jumlah biaya yang dipakai pada satu kali produksinya ialah Rp 759.188,31. Penerimaan kotor dari agroindustri kicimpring "Samisuka" sebesar Rp 1.120.000 dari hasil produksi sebanyak 140 bungkus dengan harga jual Rp 8.000/bungkus, setelah dikurangi biaya total maka keuntungan bersih yang di dapat adalah Rp. 360.811,69, dengan nilai R/C 1,48. Artinya setiap biaya Rp. 1 yang dikeluarkan memperoleh penerimaan $\mathrm{Rp}$ 1,48 maka mendapatkan keuntungan sebesar $\mathrm{Rp}$ 0,48, sehingga usaha agroindustri kicimpring "Samisuka" tersebut artinya menguntungkan.

\section{KESIMPULAN DAN SARAN}

\section{Kesimpulan}

Berdasarkan dari hasil dan juga pembahasan, maka kesimpulannya adalah sebagai berikut:

1. Total keseluruhan biaya yang dikeluarkan oleh agroindustri kicimpring "Samisuka" di Desa Cibongas Kecamatan
Pancatengah Kabupaten Tasikmlaya pada satu kali produksinya yaitu sebesar Rp 759.188,31, penerimaan $\operatorname{Rp} 1.120 .000$. sehingga memperoleh pendapatan sebesar Rp 360.811,69 per satu kali produksinya, dari keseluruhan bahan baku yang digunakan sebanyak $50 \mathrm{~kg}$.

2. Besarnya nilai $\mathrm{R} / \mathrm{C}$ pada agroindustri kicimpring "Samisuka" adalah Rp 1,48. Artinya untuk setiap biaya Rp 1 yang dikeluarkan akan mendapatkan penerimaan sebesar Rp 1,48 dan pendapatan yang diterima sebesar $\mathrm{Rp}$ 0,48. Jika, nilainya lebih dari satu artinya pengusaha kicimpring "Samisuka" ini menguntungkan.

\section{Saran}

Berdasarkan dari hasil kesimpulan, maka saran yang dapat diambil sebagai berikut:

1. Jika dilihat dari pendapatan bersihnya serta nilai R/C yang diperoleh pada kicimpring 
"Samisuka" untuk satu kali produksi maka agroindustri kicimpring "Samisuka" diharapkan salah satunya menjadi sumber alternatif dan pendapatan.

2. Supaya pengusaha kicimpring "Samisuka" bisa mempertahankan usaha serta konsisten untuk mau mengembangkan usahanya yaitu dengan cara meningkatkannya produksi dan mutu produksi maka pendapatan yang diperoleh akan meningkat. Dengan begitu diharapkan akan peenyerapan tenaga kerja lebih banyak lagi, tiada lain tujuannya mengurangi pengangguran di Desa Cibongas Kecamatan Pancatengah Kabupaten Tasikmlaya.

\section{DAFTAR PUSTAKA}

Wargiono, J. 2007. Sekenario Pengembangan Ubi Kayu Mendukung Program Penyediaan Bahan Baku Biofuel. Risalah
Seminar 2006 Penelitian dan Pengembangan Tanaman Pangan Puslitbangtan Bogor Hal 1-14, Bogor.

Kusumawardani, $\quad$ Fenny. 2009. Optimalisasi Output dan Nilai Tambah Agroindustri Belimbing Manis sebagai Upaya Peningkatan Pendapatan Studi Kasus di Perusahaan Cemara Sari Kelurahan Karangsari Kecamatan Sukorejo Kota madya Blitar. Skripsi. Fakultas Pertanian Universitas Brawijaya.

Arief Furchan, Pengantar Metoda Penelitian Kualitatif, (Surabaya: Usaha Nasional, 1992), hal 21.

Nazir, M. 2009. Metode Penelitian. Bogor:

Ghalia Indonesia.Sugiyono. 2010. Metode Penelitian Pendidikan Pendekatan Kuantitatif, Kualitatif, dan R\&D. Bandung: Alfabeta.

Suratiyah, K. $2006 . \quad$ Ilmu Usahatani.Jakarta: Penebar Swadaya.

Rodjak, A. 2006. Manajemen Usahatani. Bandung: Pustaka Giratuna.

Mulyadi. 2009. Akuntansi Biaya. Yogyakarta : STIE YPKPN 